\title{
Ovarian follicular development in mink (Mustela vison)
}

\author{
D. A. Douglas*, R. A. Pierson and B. D. Murphy* ${ }^{\dagger}$ \\ Reproductive Biology Research Unit, Department of Obstetrics and Gynaecology, \\ Royal University Hospital, University of Saskatchewan, Saskatoon, Saskatchewan, Canada
}

\begin{abstract}
Ovarian follicular dynamics were studied during the breeding season, before and after ovulation in mink. Nulliparous female mink were stimulated to ovulate with an injection of $4 \mu \mathrm{g} \mathrm{GnRH}$. Ovaries from three animals were collected on days 0, 2, 3, 4, 5, 6 and 7 after hormone treatment. A second dose of GnRH was administered on day 8 and ovaries were collected from three animals on day 9. Corpora lutea and follicles were identified in histological sections and follicles were classified by stage of development, healthy versus atretic, and by diameter. Preovulatory follicles (diameter $0.7-1.0 \mathrm{~mm}$ ) were present in the ovaries of all animals on day 0 and these responded to $\mathrm{GnRH}$ treatment by ovulating. A synchronized wave of follicular development occurred following ovulation. Changes in follicle populations indicated that follicles are recruited from the small antral follicle class $(0.2-0.4 \mathrm{~mm})$ into the $0.4-0.6 \mathrm{~mm}$ class, with the first defined changes occurring between days 2 and 4 . From the recruited group, a smaller cohort of follicles is selected to become the dominant follicles between days 4 and 6 , and these acquire the ability to respond to a stimulus which induces ovulation at diameters of $>0.7 \mathrm{~mm}$. The ovaries of unmated mink also contained substantial numbers of large, degenerating, luteinized, unruptured follicles. These degenerating, luteinized follicles are considered to represent the demise of large follicles that failed to receive an ovulatory stimulus.
\end{abstract}

\section{Introduction}

The mink (Mustela vison) has reproductive characteristics that influence its pattern of follicular development, including a seasonal reproductive cycle, induced ovulation and a period of embryonic diapause (Hansson, 1947; Enders, 1952). In the Northern hemisphere, the mink breeding season occurs from late February to March. There is no clear transition between pro-oestrus and oestrus, and behavioural oestrus is not well defined (Hansson, 1947; Travis et al., 1978). Copulation, ovulation and pregnancy do not shorten, nor does the absence of mating lengthen, the interval over which the female will accept the male (Enders, 1952; Elofson et al., 1989).

Animals can mate and ovulate for the first time on any day of the breeding season (Enders, 1952; Elofson et al., 1989). Two hypotheses have been proposed to explain the continual presence of preovulatory follicles in unmated animals. The first is that a cohort of follicles develops and is maintained until the end of the breeding season, or until an ovulatory stimulus occurs (Elofson et al., 1989; Lagerkvist et al., 1992). The second is that there is continuous overlapping development and regression of follicles throughout the breeding season, so that a new group of follicles with ovulatory capability is always present (Enders, 1952; Gilbert and Bailey, 1967).

\footnotetext{
*Present address: Centre de recherche en reproduction animale, Université de Montréal, Faculté de médecine vétérinaire, St Hyacinthe, Québec J2S 7C6, Canada.

† Correspondence.

Received 13 July 1993.
}

A feature of reproduction of mink is the capacity to mate, ovulate and successfully conceive more than once during the breeding season. Subsequent copulations stimulate subsequent ovulations if there is a sufficient interval between matings. At days $1-4$ between matings, a second ovulation will not occur; at days 5-6 some animals display a second ovulation and, if 7 or more days intercede, a second ovulation usually occurs (Hansson, 1947).

The first objective of this study was to monitor changes in follicle populations after ovulation to determine the ovarian events that result in the requirement for an interval of 7 days between fertile matings. The second objective was to evaluate follicle populations in unmated mink, to investigate the basis for the presence of preovulatory follicles throughout the breeding season.

\section{Materials and Methods}

\section{Animals and techniques}

Nulliparous pastel female mink (Mustela vison), purchased from the Montgomery Mink Ranch, Wetaskiwin, Alberta, were transported to the University of Saskatchewan before the breeding season. The animals were kept outdoors and fed a standard mink ration (National Feeds; Milk Specialties Co., New Holstein, WI) and water ad libitum. Twenty-four animals were divided randomly into eight groups of three animals each. On day 0 ( 13 March) animals from seven groups were given a $4 \mu \mathrm{g}$ injection of GnRH (Cystorelin: PVU, Victoriaville, PQ) a 
Table 1. Mean ( \pm SEM) number of follicles $>0.2 \mathrm{~mm}$ diameter and corpora lutea and mean ( \pm SEM) luteal diameter in ovaries of mink treated with one (ovaries collected on days 2-7) or two (ovaries collected on day 9) doses of $4 \mu \mathrm{g} \mathrm{GnRH}$. Control: ovaries collected on day 0 ; no GnRH

\begin{tabular}{|c|c|c|c|c|c|}
\hline Day & Healthy antral follicles & Atretic antral follicles & Luteinized follicles & Corpora lutea & Mean luteal diameter \\
\hline 0 & $42.7 \pm 9.0$ & $68.6 \pm 26.6$ & $9.8 \pm 1.8$ & 0 & 0 \\
\hline 2 & $77.3 \pm 32.7$ & $69.9 \pm 35.4$ & $6.7 \pm 0.3$ & $12.3 \pm 1.5$ & $1.0 \pm 0.1^{\mathrm{a}}$ \\
\hline 3 & $77.8 \pm 16.8$ & $66.0 \pm 26.6$ & $5.0 \pm 1.0$ & $10.0 \pm 1.6$ & $1.2 \pm 0.2^{b}$ \\
\hline 4 & $69.2 \pm 21.5$ & $73.6 \pm 28.4$ & $7.2 \pm 1.9$ & $12.8 \pm 3.0$ & $1.2 \pm 0.2^{b}$ \\
\hline 5 & $50.3 \pm 5.8$ & $125.3 \pm 30.7$ & $6.5 \pm 0.9$ & $6.3 \pm 1.9$ & $1.1 \pm 0.1^{a, b}$ \\
\hline 6 & $27.3 \pm 9.3$ & $97.3 \pm 30.7$ & $3.8 \pm 1.5$ & $11.0 \pm 2.7$ & $1.0 \pm 0.1^{\mathrm{a}}$ \\
\hline 7 & $35.0 \pm 15.0$ & $98.2 \pm 30.7$ & $7.0 \pm 2.7$ & $9.5 \pm 2.7$ & $1.0 \pm 0.1^{a}$ \\
\hline 9 & $32.7 \pm 14.1$ & $80.7 \pm 35.4$ & $6.0 \pm 2.0$ & $10.3 \pm 2.4$ & $1.0 \pm 0.1^{\mathrm{a}}$ \\
\hline
\end{tabular}

Values with different superscripts are significantly different $(P<0.05)$.

dose in excess of that expected to induce ovulation (Murphy, 1979, 1989). One group received no treatment and a further group received a second injection of $4 \mu \mathrm{g} \mathrm{GnRH}$ on day 8 . On the day after GnRH administration, the animals were moved indoors and maintained under fluorescent lights for the same duration as the natural photoperiod. The experiment was repeated with a further 24 animals during the following breeding season and the results were combined.

Ovaries were collected from the animals comprising one group on days 0 (no GnRH), 2, 3, 4, 5, 6, 7 (one GnRH injection) and 9 (two GnRH injections). Ovaries were fixed in Bouin's solution, dehydrated and embedded in paraffin wax. Serial sections $(7 \mu \mathrm{m})$ were prepared and stained with haemotoxylin and eosin. Every fifth section was projected onto geoval paper and the outlines of the ovary and the follicles were traced. Tracings were then used to develop threedimensional reconstructions of the ovaries in which each follicle was numbered. The largest diameter of each follicle was then determined by means of a computer digitized planimeter. A diameter perpendicular to the largest diameter was measured for each follicle and the mean of the two measurements was recorded as the diameter of the follicle.

Each follicle and corpus luteum was identified. Follicles were classified on the basis of stage of development: primary (one layer of granulosa cells), secondary (two or more layers of granulosa cells and no antrum), tertiary (antral follicles), and viability (healthy, atretic, luteinized). Tertiary healthy, early atretic and early luteinized follicles were further classified on the basis of diameter through the largest crosssection. The number of class intervals was established at five by application of Sturges' rule (Daniel, 1983), and the continuum of follicular diameters was divided into the following classes: $0.2-0.4,0.4-0.6,0.6-0.8,0.8-1.0 \mathrm{~mm}$ and $>1.0 \mathrm{~mm}$.

Atresia in tertiary follicles was classified on the basis of criteria established in mice by Byskov (1974). Tertiary stage I atretic follicles were identified by the presence of pyknotic granulosa cells, an intact basement membrane and the absence of polymorphonuclear leucocytes. Stage II atretic follicles had pyknotic granulosa cells; leucocytes were found among the granulosa cells; and the basement membrane was no longer intact. Stage III atretic follicles appeared shrunken and there were fewer pyknotic granulosa cells. Leucocyte invasion and disrupted basement membranes were similar to that seen in stage II.

\section{Statistical analyses}

The means and SEMs were calculated for each follicle class on each day of the experiment. The data were heteroscedastic by Bartlett's test (Snedecor and Cochrane, 1980). Differences in the means over the experimental period were therefore determined using the nonparametric Kruskal-Wallis test (Snedecor and Cochrane, 1980). Similarities and differences in the means between days were determined using correlation analysis and a two sample $t$ test respectively. The level of statistical significance accepted was $P<0.05$.

\section{Results}

\section{Ovulation and resultant corpora lutea}

In the first and second years of the experiment, 8 of 21 and 3 of 21, respectively, of the animals treated with GnRH did not ovulate, despite the presence of large preovulatory follicles in their ovaries. Over the two years, there were no significant differences in any of the parameters studied; the results were therefore combined. With the exception of the ovaries collected on day 0 , the results reported here are based on the animals that ovulated. On each day of the trial, ovaries from three to six animals were represented. The mean ( \pm SEM) number of corpora lutea in ovaries for all days of the experiment excluding day 0 was $10.3 \pm 0.8$ (Table 1 ). No differences in the number of corpora lutea over the period of the trial were detected by the Kruskal-Wallis test. Mean diameters of corpora lutea initially increased following ovulation and then declined over the last three days of the experiment (Table $1, P<0.01$ ).

\section{Changes in populations of healthy follicles}

No significant differences were observed in the number of healthy primary or secondary follicles over the experimental period. The values per animal ranged from $177 \pm 42.8$ to 

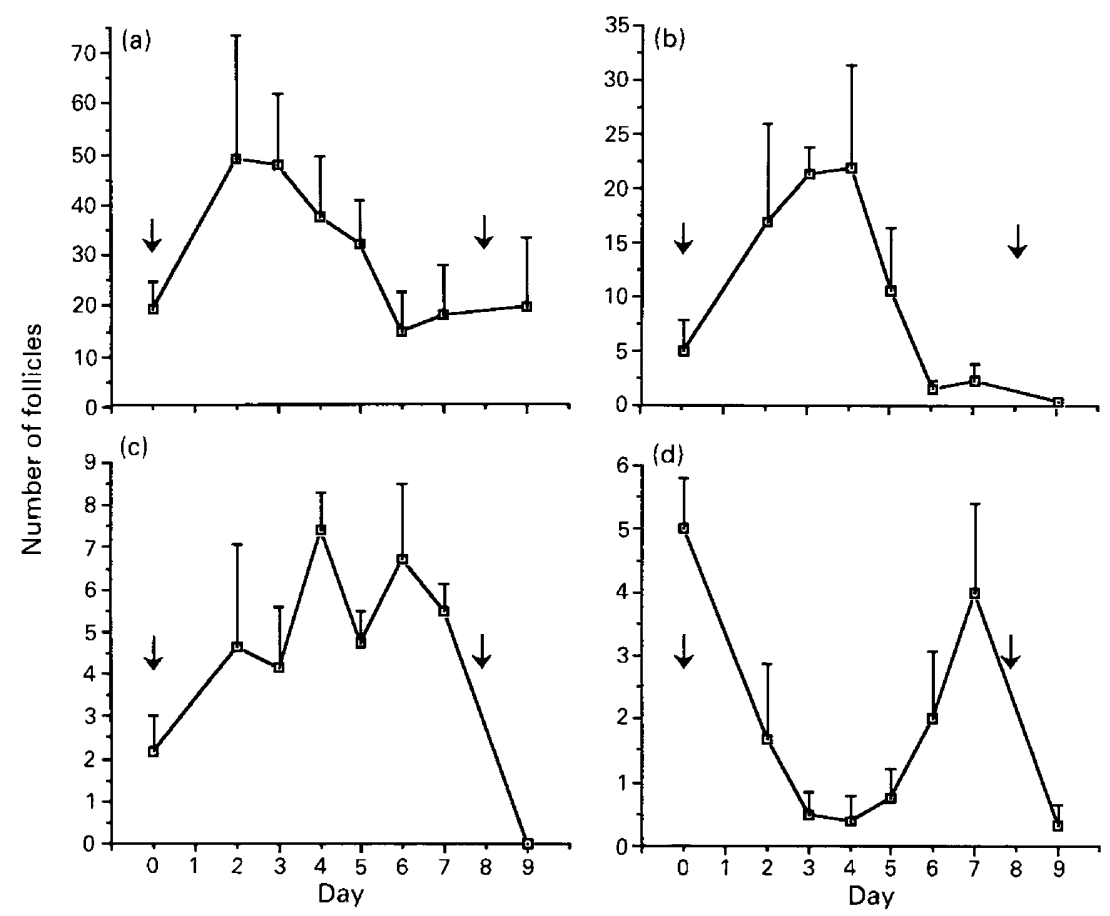

Fig. 1. Changes in the number of healthy tertiary follicles in various classes in ovaries of mink after ovulation was induced by the injection of $4 \mu \mathrm{g} \mathrm{GnRH}$ (arrow) on days 0 and 8 during the breeding season. Diameter of follicles: (a) $0.2-0.4 \mathrm{~mm}$; (b) $0.4-0.6 \mathrm{~mm}$; (c) $0.6-0.8 \mathrm{~mm}$ and (d) $0.8-1.0 \mathrm{~mm}$.

$352 \pm 56.4$ for primary follicles and from $127.2 \pm 29.3$ to $223.0 \pm 33.0$ for secondary follicles, respectively. Few atretic follicles could be identified in the preantral follicle groups. When present, atresia manifested as degeneration of the oocyte, followed by degeneration of the granulosa cells.

No differences were observed in the mean number of tertiary follicles per animal over the experimental period (Table 1). The number of follicles classified as tertiary stage I atretic, ranged from $17.67 \pm 4.89$ to $57.3 \pm 14.0$, tertiary stage II atretic $19.0 \pm 7.94$ to $57.7 \pm 34.4$ and tertiary stage III atretic $113.7 \pm 29.4$ to $261.0 \pm 81$.9. There was an increase in the number of healthy tertiary follicles of diameter $0.2-0.4 \mathrm{~mm}$ on days 2,3 and 4 of the trial, but this increase was not significant (Fig. 1a).

There were significant differences $(P<0.05)$ in the number of healthy follicles in the $0.4-0.6 \mathrm{~mm}$ class over the experimental period. The mean number of $0.4-0.6 \mathrm{~mm}$ healthy follicles per animal was greatest on days 2, 3 and 4 and these were statistically different from the mean numbers at day 0 , and days $6-9(P<0.05)$. There were few follicles in the $0.4-0.6 \mathrm{~mm}$ class on day 6 and their number remained low throughout the remainder of the experimental period (Fig. 1b).

The number of healthy follicles of $0.6-0.8 \mathrm{~mm}$ diameter differed over the experimental period $(P<0.002)$. The mean number of follicles in this class increased after the ovulatory stimulus on day 0 and remained relatively constant from days $2-7$. After the second ovulatory stimulus, there were no $0.6-0.8 \mathrm{~mm}$ healthy follicles present (Fig. Ic).
The number of follicles in the $0.8-1.0 \mathrm{~mm}$ class also varied over the experimental period $(P<0.005)$. Corpora lutea, but no large follicles, were observed on day 2 . The number of $0.8-1.0 \mathrm{~mm}$ follicles remained low until day 5 , but increased on days 6 and 7 (Fig. Id). Follicles in the $>1.0 \mathrm{~mm}$ class were found only in ovaries collected on day 0 (before $\mathrm{GnRH}$ was given) and on day 9 ( $24 \mathrm{~h}$ after the second injection of $\mathrm{GnRH}$, and before the second ovulation).

The number and size of the largest follicles $(>0.6 \mathrm{~mm})$ increased from the nadir at days 3 and 5 after GnRH treatment. The mean number of follicles $>0.6 \mathrm{~mm}$ was lowest on day 3 but increased $(P<0.05)$ on days $4-7$ (Fig. 2a). Over the same period the mean diameter of these follicles increased from $0.69 \pm 0.02 \mathrm{~mm}$ to $0.77 \pm 0.01 \mathrm{~mm}(P<0.001)$. After the second GnRH injection, there was a marked increase in the mean follicle diameter from $0.77 \pm 0.01 \mathrm{~mm}$ on day 7 to $1.40 \pm 0.02 \mathrm{~mm}$ on day 8 (Fig. 2b).

\section{Atretic follicles}

Most atretic follicles were in the $0.2-0.4 \mathrm{~mm}$ class $(68.5 \%)$ and there was an increase up to day 5 , but this was not significant $(0.05>P>0.1)$ (Fig. 3a). There were no stage I atretic follicles in the $0.4-0.6 \mathrm{~mm}$ range on day 0 . After the first GnRH treatment, the mean number of the $0.4-0.6 \mathrm{~mm}$ stage I atretic follicles ranged from 4 to 8 and after the second GnRH injection the number fell to almost zero (Fig. $3 \mathrm{~b}$ ). Few stage I atretic follicles were found with a diameter $>0.5 \mathrm{~mm}$ 

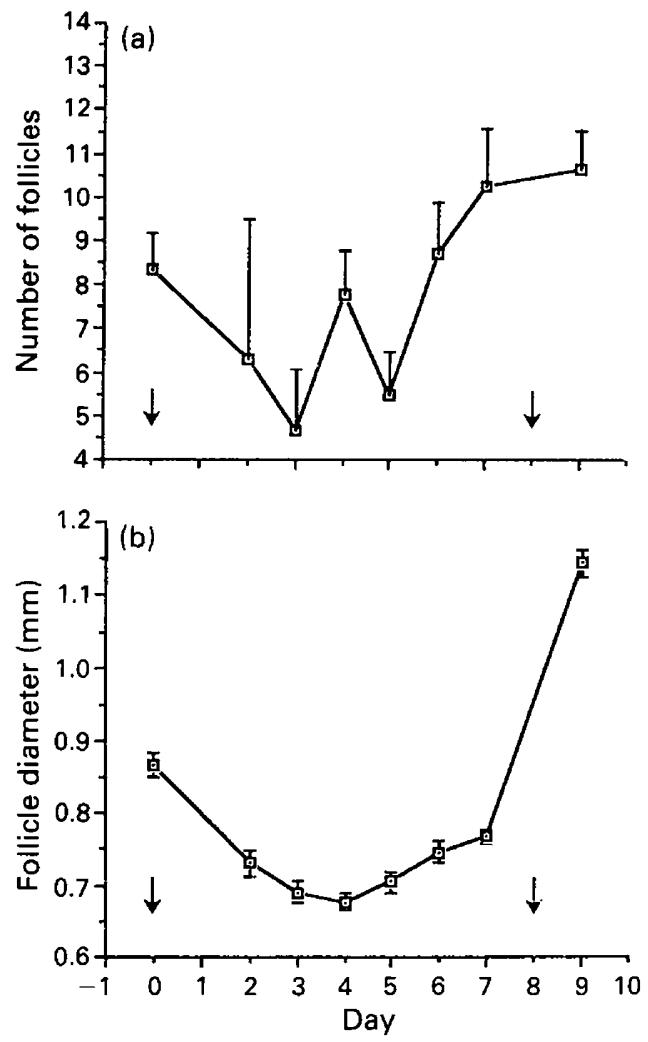

Fig. 2. Changes in (a) the number and (b) the size of the largest follicles ( $>0.6 \mathrm{~mm}$ diameter) present in the ovaries of mink after ovulation was induced by $4 \mu \mathrm{g} \mathrm{GnRH}$ (arrow) on days 0 and 8 during the breeding season.

( $<8 \%$ of atretic follicle population) and none was found with a diameter $>0.7 \mathrm{~mm}$.

\section{Luteinized follicles}

Examples of the pre- and post-ovulation mink ovaries are shown (Fig. 4a,b, respectively). The ovaries also contained luteinized, unruptured follicles, of two distinct types. The first type appeared identical to mink corpora lutea resulting from ovulation, except for the presence of the remnants of the zona pellucida (Fig. 4c). These corpus luteum-like luteinized unruptured follicles were found only in animals subjected to $\mathrm{GnRH}$ treatment and accounted for $5 \%$ of the corpora lutea observed. The second type of luteinized unruptured follicles was characterized by the partial luteinization of the granulosa cell layer in tertiary follicles of otherwise normal appearance. Three stages of the latter form of luteinization could be identified. In stage I, follicles had pockets of luteinized granulosa cells bordering the antrum, an intact basement membrane and an apparently degenerate oocyte surrounded by healthy cumulus cells (Fig. $4 \mathrm{~d}$ ). The mean diameter of stage I degenerating luteinized unruptured follicles was $1.08 \pm 0.2 \mathrm{~mm}$. Stage II luteinized unruptured follicles had further luteinization of the granulosa cells and some of the luteinized cells were flattened, and the degenerate oocyte was located next to the remainder of the

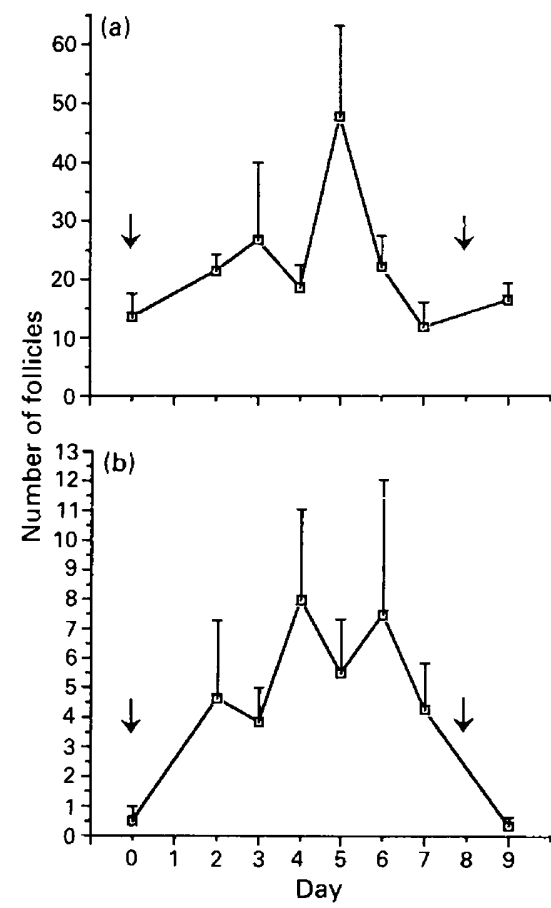

Fig. 3. Changes in the number of stage I atretic follicles (a) $0.2-$ $0.4 \mathrm{~mm}$ diameter and (b) $0.4-0.6$ diameter in ovaries of mink after ovulation was induced by injection of $4 \mu \mathrm{g} \mathrm{GnRH}$ (arrows) on days 0 and 8 during the breeding season.

follicle wall (Fig. 4e). Stage III luteinized unruptured follicles were characterized by the collapse of the follicle so that the antrum was no longer visible. The few granulosa cells that remained were flattened and irregular. The oocyte was completely degenerate and only remnants of the zona pellucida remained (Fig. 4f). Degenerating luteinized unruptured follicles were found in all animals, with the highest numbers usually occurring in ovaries collected on day 0 .

\section{Discussion}

The results reported here demonstrate the presence of a synchronized wave of follicular development in mink after ovulation. The data indicate that the large preovulatory follicles, which are present in the mink ovary on day 0 , ovulate in response to $\mathrm{GnRH}$ treatment which simulates the mating stimulus. These structures are present in the ovary in the form of corpora lutea on day 2. This conclusion is strengthened by the observation that no corpora lutea or corpus luteum-like luteinized unruptured follicles were found in animals that had not been induced to ovulate. The temporal variation in the number of healthy small tertiary follicles present after ovulation indicates that follicles are recruited from the $0.2-0.4 \mathrm{~mm}$ class into the $0.4-0.6 \mathrm{~mm}$ class between days $I$ and 4 after $\mathrm{GnRH}$ treatment. This recruitment is reflected in the transient increase in the number of $0.4-0.6 \mathrm{~mm}$ follicles between days 2 and 4 . From the pool of recruited follicles it appears that a smaller cohort of follicles is selected between days 4 and 6 to become the dominant follicles that can respond to the next ovulatory 

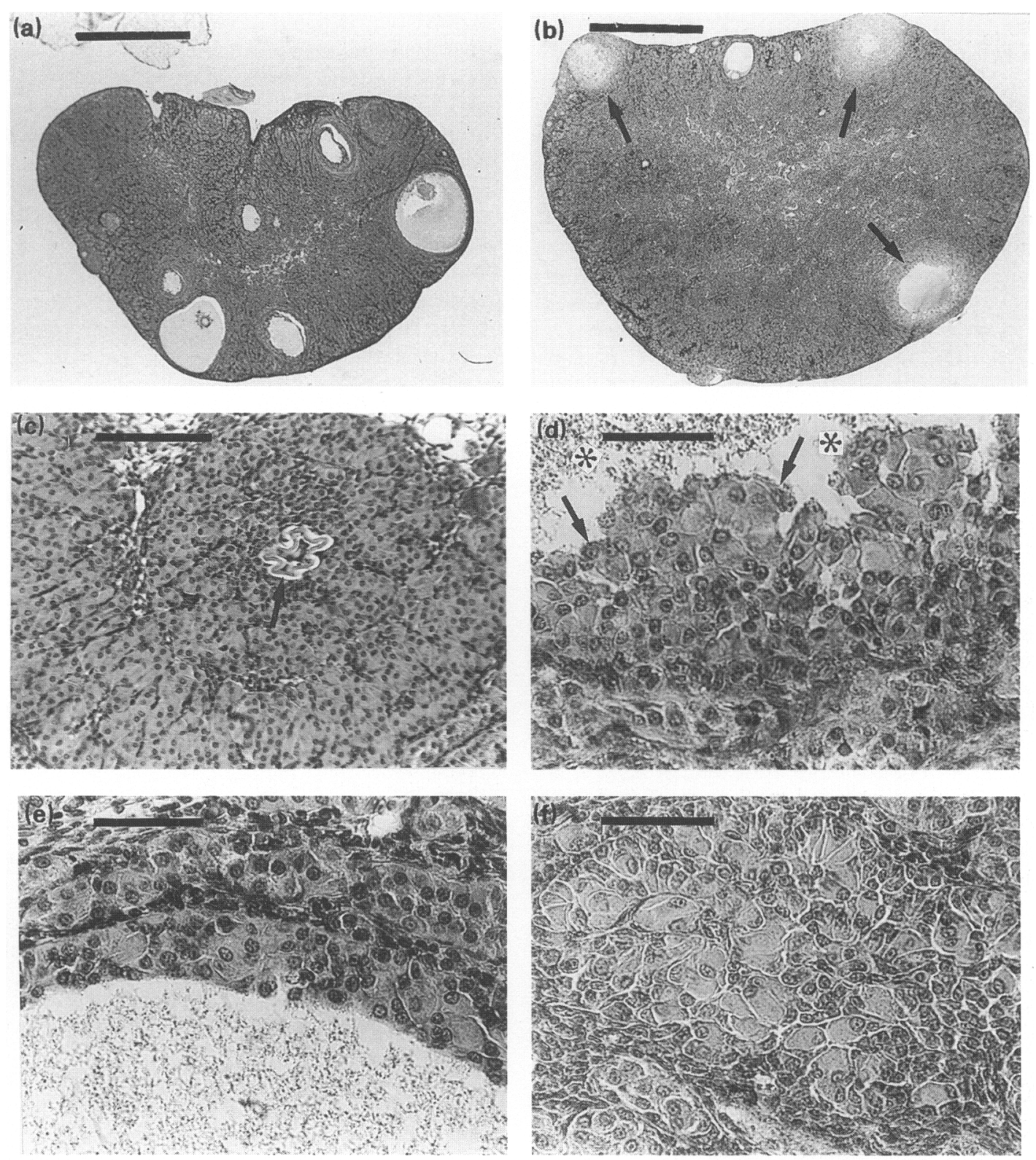

Fig. 4. Sections of ovaries from mink (a) before treatment with $4 \mu \mathrm{g} \mathrm{GnRH}$ and (b) $72 \mathrm{~h}$ after treatment with GnRH. Arrows indicate newly formed corpora lutea. (c) Type 1 luteinized unruptured follicle, similar to a normal mink corpus luteum except for the presence of remnants of the zona pellucida (arrows). (d) Type 2 luteinized unruptured follicle in stage I of degeneration characterized by the presence of isolated pockets of luteinized granulosa cells (arrows) bordering the follicle antrum (*). (e) Type 2 luteinized unruptured follicle in stage II of degeneration characterized by the degeneration of the luteinized cells. (f) Type 2 luteinized unruptured follicles in stage III of degeneration characterized by the collapse of the follicle. Scale bars represent $2 \mathrm{~mm}((\mathrm{a})-(\mathrm{b})), 0.7 \mathrm{~mm}(\mathrm{c})$ and $0.2 \mathrm{~mm}((\mathrm{~d})-(\mathrm{f}))$.

stimulus. This conclusion is supported by the observation that all but a few of the recruited follicles became atretic by day 6 . The remaining healthy follicles appeared to continue to grow until the next ovulatory stimulus, as indicated by the increase in diameter in the follicles $>0.6 \mathrm{~mm}$ between days 6 and 7 .

Selection of the dominant follicles in mink appeared to occur when follicles were at half of their maximum diameter (approximately $0.5 \mathrm{~mm}$ ). This finding is supported by the observation that only a few stage I atretic follicles with diameters in the large size classes $(>0.5 \mathrm{~mm})$ could be identified. There were none with diameters $>0.7 \mathrm{~mm}$. It is noteworthy that it is at this critical selection stage $(0.5-0.7 \mathrm{~mm})$ that follicle growth in mink is arrested during anoestrus (Enders, 1952).

We suggest that if a second ovulatory stimulus does not occur, the dominant follicles continue to grow to $1.0-1.1 \mathrm{~mm}$, which is the maximum size observed in mink during the breeding season (Hansson, 1947; Enders, 1952). 
Selection of the dominant follicles occurred at diameters between 0.5 and $0.7 \mathrm{~mm}$. However, we surmise that only those in excess of $0.7 \mathrm{~mm}$ had the capacity to ovulate. This conclusion is based on the observation that all of the dominant follicles present in the ovary on day 7 had diameters $>0.7 \mathrm{~mm}$ and there were few other tertiary follicles. In addition, the number of dominant follicles on day 7 correlated $(P<0.001)$ with the number of follicles showing imminent signs of ovulation on day 9 .

The present observations are consistent with those of Hansson (1947), who observed that when there was an interval of 1-4 days between two matings, a second ovulation was not stimulated by the second mating. From the results reported here, it is concluded that most of the large follicles in the ovary on day 0 ovulated in response to the GnRH injection. The few large follicles present by day 2 are believed to be destined to degenerate, since none was present on day 3. Hansson (1947) reported that second ovulations do not usually occur if the interval between matings is 5-6 days. The lack of follicles of diameter $>0.7 \mathrm{~mm}$ by day 6 after $\mathrm{GnRH}$-induced ovulation further suggests that it is these follicles which have the capacity to ovulate. Finally, Hansson (1947) determined that, if the interval between matings was extended to 7 or more days, most of the animals ovulated in response to a second mating. By day 7, we found that the ovaries of all the animals had follicles $>0.7 \mathrm{~mm}$, but that there were few of these follicles remaining on day 9, after a second GnRH injection. Our results are also consistent with observations made by Lagerkvist $e t$ al. (1992) who determined that the concentrations of oestradiol were greatest on the day of the first mating and peaked again approximately one week later. The timing of the second oestrogen peak suggested that there was a wave of follicular development after the first ovulation.

A consistent course of follicular development in mink after ovulation is contrary to the findings of Enders and Enders (1963) who reported widely varying stages of follicular development at 6 and 10 days after mating. However, in that study, the animals were not synchronized with respect to the day of the breeding season on which they were mated.

The design of the experiment reported here also allowed for the examination of follicle populations before the first mating. All of the ovaries from unmated mink collected on 13 March (day 0 ) contained follicles $>0.7 \mathrm{~mm}$. This finding is consistent with the findings of Elofson et al. (1989) who reported the presence of follicles with diameters $>0.5 \mathrm{~mm}$ in unmated mink from 14 March to 2 April.

There was an initial increase in the mean luteal diameter on the first day after ovulation, followed by a decline on days 5-7 after the GnRH stimulus. This result is considered to reflect the initial luteal proliferation followed by luteal inactivation associated with embryonic diapause and is consistent with the observations of Hansson (1947).

There was no difference in the number of corpora lutea per animal in either year of the study indicating that when ovulation occurred, it was uniform. The mean number of corpora lutea $(10.3 \pm 0.8)$ compared favorably with the number reported by Hansson (1947) in mink that had mated once (12.0 \pm 1.9$)$.

Several of the animals in the first year of the trial and a few in the second year failed to ovulate. The reasons for this failure are unknown. Ovaries from these animals contained large preovulatory follicles. These and other follicles were present in the same frequencies as those found in ovaries collected from animals before GnRH treatment (day 0 ). Thus, it is unlikely that the animals that failed to ovulate represent a non-responsive subpopulation. The dose of GnRH administered was twice that which was successfully used to replace the first mating in mink (Murphy, 1977, 1979) and in excess of that required to replicate the LH surge induced by cervical stimulation (Murphy, 1989). The trial was initiated on the same day of the breeding season (13 March) in both years of the investigation. Adams (1981) showed that unmated mink can be induced to ovulate much earlier in the breeding season than 13 March by administration of hCG. Thus, it is unlikely that the failure to ovulate was due to administering the treatment too early. The most plausible explanation is that the variable response was an artifact of the freezing and thawing of the GnRH solution which was administered when ambient temperatures were $-30^{\circ} \mathrm{C}$.

We observed that the ovaries of unmated mink contained a number of large luteinized unruptured follicles, as previously reported by Enders (1952), Venge (1959), Møller (1974), Elofson et al. (1989) and Lagerkvist et al. (1992). The experiment reported here revealed that follicles in the earliest stage of this luteinization-degeneration process had diameters of approximately the same size as that of the largest follicles observed in mink during the breeding season (Hansson, 1947; Enders, 1952). We suggest that these are the preovulatory follicles that develop during the breeding season but do not receive the stimulus to ovulate. Studies in other induced ovulators support this hypothesis, for example preovulatory cat follicles are transformed into luteal-like tissue if mating does not occur during oestrus (Dawson and Friedgood, 1940) and in llama regressing follicles luteinize if follicles have been exposed to an LH surge (Bravo et al., 1991).

Repeated observations on follicle development in mink are difficult to obtain as the degree of resolution of diagnostic imaging techniques can distinguish only the largest preovulatory follicles. Observations by laparoscope, as used in rabbits (Hill and White, 1934), cannot be used in mink owing to the relatively smooth surface of the ovary during the breeding season. The presence of degenerating preovulatory follicles in unmated mink early in the breeding season that we observed provides indirect evidence that follicle turnover occurs. The simultaneous occurrence of large follicles in intact and degenerating states further suggests that there are waves of follicular development before the first mating. These observations are in conflict with the view that a cohort of follicles develops and is maintained until the mating stimulus occurs (Elofson et al., 1989 and Lagerkvist et al., 1992). Further work, either by pulse labelling of dividing follicular cells or by improved imaging techniques is needed before the presence of follicular waves can be confirmed in mink.

The findings of this study are summarized (Fig. 5). We conclude that there is a synchronized wave of follicular development in mink after ovulation during the breeding season. Follicles are recruited from the small tertiary follicle classes into the $0.4-0.6 \mathrm{~mm}$ class between days 1 and 4 after mating. From the recruited group, a smaller cohort of follicles is selected between days 4 and 6 and these follicles continue to 


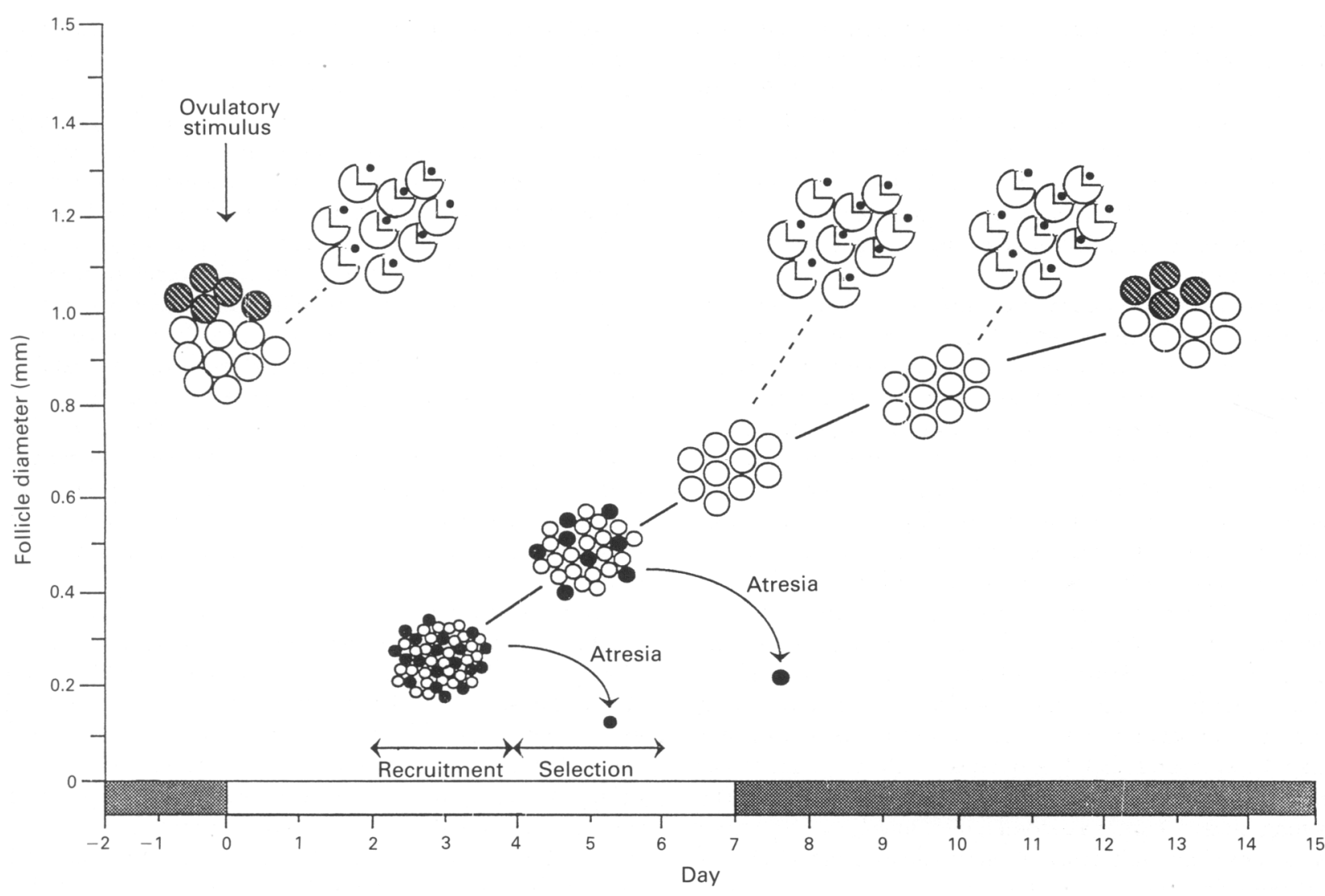

Fig. 5. Schematic representation of follicular development in mink between ovulations induced by injections ( $4 \mu \mathrm{g})$ of $\mathrm{GnRH}$ at an interval of 8 days during the breeding season. $O$ : healthy tertiary follicles; : tertiary stage I atretic follicles; tertiary stage I luteinized follicles. stimulated; (-): the course of follicular development if there is no ovulatory stimulus; (- - - ): the course of follicular development following an ovulatory stimulus. Mating or $\mathrm{GnRH}$ treatment induces ovulation in a cohort of follicles $>7 \mathrm{~mm}$ in diameter (days 0-2). The subsequent wave of follicles develops from a pool of $0.2-0.4 \mathrm{~mm}$ antral follicles on days $2-4$. From the recruited pool, some follicles $(0.4-0.6 \mathrm{~mm})$ are selected between days 4 and 6 . These become the follicles of $>0.7 \mathrm{~mm}$ that respond to the next ovulatory stimulus (days 7-10). If this stimulus is absent, some or all of these follicles degenerate by a process of luteinization (days 13-14).

grow and become the dominant follicles that will respond to the next ovulatory stimulus. In addition, we found that the ovaries from all unmated animals contained large, healthy follicles considered capable of responding to the ovulatory stimulus. The ovaries from unmated animals also contained a number of large luteinized unruptured follicles which may represent the process by which large follicles, not subject to an ovulatory stimulus during the breeding season, are eliminated from the ovary. The presence of healthy and degenerating dominant follicles suggest that there may be a continued turnover in the dominant follicle population in mink before the first mating.

This report is dedicated to the memory of the late James $\mathrm{W}$. Montgomery. The authors thank T. Clement and R. Montgomery of the Montgomery Fur Ranch for supplying animals, E. Rasmussen for animal care, M. C. Ouellet and M. Blaquière for the figures and M. Sicotte for frequent revision of the manuscript. This study was supported by Operating Grant 137013 from the Natural Sciences and Engineering Research Council of Canada to B. D. Murphy.

\section{References}

Adams CE (1981) Observations of the induction of ovulation and the expulsion of uterine eggs in mink (Mustela vison) Journal of Reproduction and Fertility 63 241-248

Bravo PW, Stabenfeldt GH, Lasley BL and Fowler ME (1991) The effect of ovarian follicle size on pituitary responses to copulation in domesticated South American camelids Biology of Reproduction 45 553-559

Byskov AG (1974) Cell kinetic studies of follicular atresia in the mouse ovary Joumal of Reproduction and Fertility 37 277-285

Daniel WW (1983) Biostatistics: a foundation for analysis of the health sciences. 3rd Edn. John Wiley and Sons, New York

Dawson AB and Friedgood HB (1940) The time and sequence of preovulatory changes in the cat ovary after mating or mechanical stimulation of the cervix uteri. Anatomical Record 76 411-429

Elofson L, Lagerkvist G, Gustafsson H and Einarsson S (1989) Mating systems and reproduction in the mink. Acta Agriculturae Scandinavica 39 23-41

Enders RK (1952) Reproduction in the mink (Mustela vison) Proceedings of the American Philosophical Society $96691-779$

Enders RK and Enders AC (1963) Morphology of the female reproductive tract during delayed implantation in the mink. In Delayed Implantation, pp 129-139 Ed. AC Enders. Chicago University Press, Chicago 
Gilbert FF and Bailey ED (1967) The effect of visual isolation on reproduction in the female ranch mink (Mustela vison) Joumal of Mammalogy 48 $113-118$

Hansson A (1947) The physiology of reproduction in mink with special reference to delayed implantation Acta Zoologica 28 1-136

Hill $M$ and White WE (1934) The growth and regression of follicles in the oestrous rabbit Journal of Physiology 80 174-179

Lagerkvist G, Einarsson J, Forsberg M and Gustafsson H (1992) Profiles of oestradiol-17 $\beta$ and progesterone and follicular development during the reproductive season in mink (Mustela vison) Journal of Reproduction and Fertility 94 11-21

Moller OM (1974) Plasma progesterone before and after ovariectomy in unmated and pregnant mink, Mustela vison Joumal of Reproduction and Fertility $37 \quad 367-372$
Murphy BD (1977) Effects of synthetic GnRH on litter size in ranch mink bred once or twice Theriogenology $6463-467$

Murphy BD (1979) Effects of GnRH on plasma LH and fertility in mink Canadian Joumal of Animal Science $5925-33$

Murphy BD (1989) Reproductive biology of female mustelids. In Conservation biology and the black-footed ferret, pp 107-123 Eds US Seal, ET Thome, MA Bogan and SH Anderson. Yale University Press, New Haven

Snedecor GW and Cochrane WG (1980) Statistical Methods. The Iowa State University Press, Ames

Travis HF, Pilbeam TE, Gardner WJ and Cole RS (1978) Relationship of vulval swelling to estrus in mink Journal of Animal Science 46 219-224

Venge $O$ (1959) Reproduction in the fox and mink Animal Breeding Abstracts 27 29-145 